\title{
The Psychological Impact Analysis of Novel COVID-19 Pandemic in Health Sciences Students: A Global Survey
}

\author{
Thelma Farasat Bashir ${ }^{1}$ Sobia Hassan ${ }^{2}$ Afsheen Maqsood ${ }^{3}$ Zafar Ali Khan ${ }^{4} \quad$ Rakhi Issrani $^{5}$ \\ Naseer Ahmed ${ }^{6,7, \odot}$ Evangel Faraz Bashir ${ }^{8}$
}

\footnotetext{
${ }^{1}$ Department of Community Dentistry, Altamash Institute of Dental Medicine, Karachi, Pakistan

${ }^{2}$ Department of Pathology, Altamash Institute of Dental Medicine, Karachi, Pakistan

${ }^{3}$ Department of Oral Pathology, Altamash Institute of Dental Medicine, Karachi, Pakistan

${ }^{4}$ Department of Oral and Maxillofacial Surgery and Diagnostic Sciences, College of Dentistry, Jouf University, Sakaka, Al Jouf, Kingdom of Saudi Arabia

${ }^{5}$ Department of Preventive Dentistry, College of Dentistry, Jouf University, Sakaka, Al Jouf, Kingdom of Saudi Arabia

${ }^{6}$ Department of Prosthodontics, Altamash Institute of Dental Medicine, Karachi, Pakistan

${ }^{7}$ Scholar Prosthodontics Unit, School of Dental Sciences, University Sains Malaysia, Kubang Kerian, Kelantan, Malaysia

${ }^{8}$ Department of Pharmacology, Jinnah Medical and Dental College, Karachi, Pakistan
}

Eur J Dent:2020;14(suppl S1):S91-S96

\author{
Address for correspondence Zafar Ali Khan, BDS, FCPS, \\ Department of Oral and Maxillofacial Surgery and Diagnostic \\ Sciences, College of Dentistry, Jouf University, Sakaka, Al Jouf \\ 72345, Kingdom of Saudi Arabia (e-mail: dr.zafar.khan@jodent.org).
}

\begin{abstract}
Keywords

- health sciences students

- psychological impact

- novel

COVID-19 pandemic

Objective To evaluate the anxiety and depression amid novel coronavirus disease-19 (COVID-19) pandemic in health sciences students around the globe.

Materials and Methods This cross-sectional observational study comprised 523 health science students. A well-structured online questionnaire consisting of closed-ended questions based on student's general information, Patient Heath Questionnaire (PHQ)-9 and Generalized Anxiety Disorder (GAD)-7 scales were used to assess the psychological impact of COVID-19.

Statistical Analysis SPSS-25 was used to analyze the outcome of this study. Multiple linear regression analysis test was used to assess variables which had impact on PHQ-9 and GAD-7 scores among the participants. A p-value of $\leq 0.05$ was considered as statistically significant.

Results Among the 523 participants, 365 (69.55\%) students were from developing countries and 158 (30.21\%) from developed countries; 424 (81.1\%) students were tested negative for COVID-19 and 99 (18.9\%) had suffered from severe acute respiratory syndrome coronavirus 2 infection during pandemic. The mean GAD-7 and PHQ-9 scores were $7.16 \pm 5.755$ and $7.30 \pm 6.166$, respectively. Significant impact on anxiety levels was associated with age, gender, education status, and COVID-19 positive patient, while depression was not significantly associated with gender, COVID-19, and its reported symptoms in participants.
\end{abstract}

DOI https://doi.org/ 10.1055/s-0040-1721653 ISSN 1305-7456. (c) 2020. European Journal of Dentistry.

This is an open access article published by Thieme under the terms of the Creative Commons Attribution-NonDerivative-NonCommercial-License, permitting copying and reproduction so long as the original work is given appropriate credit. Contents may not be used for commercial purposes, or adapted, remixed, transformed or built upon. (https://creativecommons.org/licenses/ by-nc-nd/4.0/)

Thieme Medical and Scientific Publishers Pvt. Ltd. A-12, 2nd Floor, Sector 2, Noida-201301 UP, India 
Conclusion As the world is trying to contain the health effects of COVID-19, the psychological effects might take a longer time to be addressed. Our study highlights the dire need to identify mental well-being of health science students as this may have a direct impact on their professional commitments and future responsibilities.

\section{Introduction}

Wuhan (Hubei, China) suffered a massive spread of coronavirus disease-19 (COVID-19), which not only affected China but also progressed around the globe. ${ }^{1-3}$ According to John Hopkins University, September 29, 2020, more than 33,431,133 confirmed cases were reported along with $1,003,168$ deaths worldwide. ${ }^{4}$ Considering the contagious nature of COVID-19, World Health Organization (WHO) introduced the concept of social distancing as a measure to reduce the transmission of infection. ${ }^{5}$ This concept was widely appreciated as world history showed that exercising quarantine can help battle against and grip the spread of infectious disease such as cholera, the plague, Ebola, and severe acute respiratory syndrome (SARS). ${ }^{6}$ With the same concept, Pakistani government enforced gradual shutdown of schools, universities, and various industries from 16th March, eventually prohibiting all nonessential activities from March 21, 2020. Although lockdown became a necessity for reducing the emergence of new cases, the drawbacks affected the underdeveloped countries much more than the developed ones. To name a few, there were economic implications, lack of access to home schooling, altered mental health, and depression as a result of challenges created by the quarantine. ${ }^{6}$ Literature suggests that psychological distress has been associated with implementation of quarantine. A study was done in Toronto during SARS 2003 infection, which concluded that posttraumatic stress disorder (PTSD) and depression were on the top of all psychological effects. ${ }^{7}$ Furthermore, it was reported that longer duration of quarantine was in direct proportion with PTSD symptoms.

American Psychological Association characterized anxiety as "a feeling described by sentiments of strain, stressed considerations, and physical changes, for example, high level of blood pressure." WHO characterizes depression as a "common mental disorder, characterized by misery, loss of intrigue or delight, feelings of blame or low self-esteem, disturbed sleep or hunger, and sentiments of sluggishness and poor concentration." 8

According to WHO, individuals who experience stress/ depression have a 10-year shorter life expectancy than general population. ${ }^{9,10}$ Moreover, suicidal tendency has been reported to be found in $\sim 11.1 \%$ of all medical students experiencing increased level of depression. ${ }^{11}$ There is growing concern over the mental health of the future clinicians as it may directly impact their professional commitment. ${ }^{12}$

Studies have been conducted in Pakistan ${ }^{13,14}$ and Saudi Arabia ${ }^{15}$ to assess stress levels in dental and medical students. However, there is scarce literature regarding the psychological well-being of health sciences students. Our study aims to cover this gap in the literature by evaluating the anxiety and depression levels in health sciences students around the globe during COVID-19.

\section{Materials and Methods}

This survey-based study was conducted between August 20, 2020, and September 20,2020. The survey included 523 adults (i.e., above the age of 18 years) students engaged in health sciences studies, that is, MBBS, BDS, pharmacist, physiotherapist, and nursing students, living in Pakistan and abroad. The convenience sampling technique was used. Ethical approval was obtained from ethical and review committee of Altamash Institute of Dental Medicine, Karachi, Pakistan (AIDM/EC/08/2020/01). A web-based questionnaire consisting of 36 closed-ended questions was constructed and validated for accuracy and consistency through Cronbach $\alpha$ and face, content validity. The internal consistency of items was ( $\alpha=0.876$ ). The questionnaire was shared with participants through social media platforms and e-mails via a digital link. A total of 592 responses were received from participants. On scrutiny, 69 forms were excluded on the basis of repetition and irrelevance to the study participants' criteria. All participants provided informed consent. The survey took 10 minutes to complete and questions were asked about their demographic data (age, gender, education, educational level, and nationality), respondents' personal situation during quarantine (having being tested for or diagnosed with COVID-19, self-reported symptoms of COVID-19), present or past intake of psychoactive medication, present or past psychological/psychiatric treatment.

The psychological impact of the pandemic and the quarantine was evaluated using two validated scales, namely, Generalized Anxiety Disorder (GAD)-7 and nine-item version of the Patient Heath Questionnaire (PHQ) depression scale. ${ }^{16,17}$ The PHQ-9 depression scale was composed of self-reported items each with a Likert scale from 0 to 20 (0-5 = mild, 6-10 = moderate, 11-15 = moderately severe, and $16-20=$ severe depression). The GAD-7 anxiety scale is a seven-item with four-point Likert-type scale ( $0=$ not at all, 1 = several days, 2 = more than half the days, and $3=$ nearly every day). GAD-7 total score for the seven item ranges from 0 to 21 . Score represents 0 to $5=$ mild, 6 to $10=$ moderate, 11 to 15 = moderately severe anxiety, and 15 to $21=$ severe anxiety.

The statistical analysis was performed using IBM SPSS Statistics software version 25. Descriptive statistics (mean, standard deviations, percentages, and frequencies) were calculated for qualitative and quantitative variables. The multiple linear regression analysis was used to assess the effect 
of age, gender, level of education being tested positive and negative for COVID-19, and its symptoms with PHQ-9 and GAD-7 scores of participants. A $p$-value of $\leq 0.05$ was considered as statistically significant.

\section{Results}

In this cross-sectional observational study, the response rate from participants was $92 \%$. The mean age of participants was $24.61 \pm 6.55$. In our study, 418 (79.9\%) were females and $105(20.1 \%)$ males. Two-thirds of participants were undergraduate students out of which 319 (61\%) were bachelor of dental surgery students while $112(21.4 \%)$ were MBBS, whereas 30 (5.8\%) were pharmacy and physiotherapy students and $62(11.9 \%)$ were other health sciences students, that is, nursing, dental care professionals, psychiatry, and technicians. In this study, 365 (69.55\%) students were from developing countries and 158 (30.21\%) from developed countries as described in - Table 1 .

Table 1 Demographic details of participants $(N=523)$

\begin{tabular}{|c|c|c|}
\hline Variables & $N$ & $\%$ \\
\hline \multicolumn{3}{|l|}{ Education field } \\
\hline MBBS & 112 & 21.4 \\
\hline BDS & 319 & 61.0 \\
\hline Pharmacy & 14 & 2.7 \\
\hline Physiotherapy & 16 & 3.1 \\
\hline Others & 62 & 11.9 \\
\hline \multicolumn{3}{|l|}{ Level of education } \\
\hline Undergraduate & 327 & 62.5 \\
\hline Graduates & 121 & 23.1 \\
\hline Postgraduate & 75 & 14.3 \\
\hline \multicolumn{3}{|l|}{ Nationality } \\
\hline Pakistani & 154 & 29.44 \\
\hline British & 33 & 6.30 \\
\hline American & 19 & 3.60 \\
\hline Canadian & 15 & 2.86 \\
\hline Indian & 17 & 3.30 \\
\hline Filipino & 14 & 2.70 \\
\hline Egyptian & 12 & 2.30 \\
\hline Malaysian & 18 & 3.44 \\
\hline Emirati & 30 & 5.73 \\
\hline Saudi Arabian & 40 & 7.64 \\
\hline Chinese & 67 & 12.81 \\
\hline Australian & 24 & 4.58 \\
\hline Norwegian & 15 & 2.86 \\
\hline Indonesian & 43 & 8.22 \\
\hline Singaporean & 22 & 4.20 \\
\hline \multicolumn{3}{|l|}{ Gender } \\
\hline Male & 105 & 20.1 \\
\hline Female & 418 & 79.9 \\
\hline
\end{tabular}

Furthermore, in this study, $424(81.1 \%)$ students were tested negative for COVID-19 and 99 (18.9\%) had suffered from SARS coronavirus 2 infection during pandemic. Out of the total positive students, 77 (14.5\%) reported for COVID-19 symptoms. Moreover, 436 (83.4\%) students were known to patients with COVID-19 symptoms. Additionally, $32(6.1 \%)$ students were using any form of medication for multiple reasons, that is, asthma, allergy, COVID-19 prophylaxis, diabetes, and arthritis.

The features of GAD-7 scale are presented in - Table 2 . The summative mean score of GAD-7 was $7.16 \pm 5.755$. The details of GAD categories were as follow: $230(44 \%)$ participants fall in mild anxiety level, 171 (32.7\%) had moderate anxiety, 61 (11.7\%) moderately severe anxiety, and 61 (11.7\%) had severe anxiety scores.

Additionally, as per multiple linear regression analysis, for GAD-7, the constant for R-squared $\left(\mathrm{R}^{2}\right)$ was 0.097 and adjusted R-squared $\left(A^{2}\right)$ was 0.089 in the equation model. Further a significant difference $(p=0.010)$ was found between the age of participants and GAD-7 scores. Similarly, a significant difference $(p=0.000)$ was also seen among gender and GAD-7 scores. However, no significant difference $(p=0.256)$ was found between education level and GAD-7 scores. No significant difference $(p=0.617)$ was found between GAD-7 and participants tested positive or negative for COVID-19. Finally, a significant difference $(p=0.020)$ was revealed between participants with symptoms of COVID-19 and GAD-7 scores (- Table $\mathbf{3}$ ).

The characteristics of PHQ-9 scale are described in - Table 4. The summative total mean score was $7.30 \pm 6.166$. The details of PHQ categories were as follow: 248 (47.4\%) participants fall in mild depression level, 155 (29.6\%) had moderate depression, 55 (10.5\%) moderately severe depression, and 65 (12.4\%) had severe depression scores.

Furthermore, for PHQ-9, the constant for $\mathrm{R}^{2}$ was 0.099 and $\mathrm{AR}^{2}$ was 0.090 in the multiple regression analysis. Moreover, a significant difference $(p=0.016)$ was found between the age of participants and PHQ-9 scores. However, no significant difference $(p=0.124)$ was seen among gender and PHQ-9 scores. A significant difference $(p=0.019)$ was found between education level and PHQ-9 scores. No significant difference ( $p=0.586$ ) was found between PHQ-9 and participants tested positive or negative for COVID-19. Similarly, no significant difference ( $p=0.138$ ) was also seen between participants with symptoms of COVID-19 and PHQ-9 scores (-Table 3).

\section{Discussion}

Literature shows that pandemic of COVID-19 has significantly affected mental health and occupation of population worldwide. ${ }^{18}$ It has been reported that prevalence of depression and anxiety is up to $44 \%$ in developing countries while in a survey done on medical students of Europe and the English speaking regions outside North America, while Azad et al reported a prevalence as high as $66.5 \% .{ }^{11,19}$ Our study population comprised health science students around the globe. We found significant impact of lockdown on mental well-being 
Table 2 Characteristics of GAD-7 scale $(N=523)$

\begin{tabular}{|l|l|l|l|}
\hline & $\begin{array}{l}\text { Over the last } 2 \text { wk, how often have you been bothered by the following } \\
\text { problems? }\end{array}$ & Mean & SD \\
\hline GAD-1 & Feeling nervous, anxious, or on edge & 1.03 & 0.986 \\
\hline GAD-2 & Not being able to stop or control worrying & 0.91 & 0.964 \\
\hline GAD-3 & Worrying too much about different things & 1.20 & 1.009 \\
\hline GAD-4 & Trouble relaxing & 0.99 & 1.006 \\
\hline GAD-5 & Being so restless that it is hard to sit still & 0.74 & 1.032 \\
\hline GAD-6 & Becoming easily annoyed or irritable & 1.18 & 1.007 \\
\hline GAD-7 & Feeling afraid as if something awful might happen & 1.08 & 1.041 \\
\hline & & $7.16^{a}$ & 5.755 \\
\hline
\end{tabular}

Abbreviations: GAD, Generalized Anxiety Disorder; SD; standard deviation.

Moderate anxiety level.

Table 3 Linear regression analysis of age, gender, students with COVID-19 symptoms, their education level with anxiety and depression amid SARS-CoV-2 pandemic $(N=523)$

\begin{tabular}{|c|c|c|c|c|c|c|}
\hline \multirow[t]{2}{*}{ Scales } & \multirow[t]{2}{*}{ Variables } & \multicolumn{2}{|c|}{ Unstandardized coefficients } & \multirow{2}{*}{$\begin{array}{l}\text { Standardized } \\
\text { coefficients } \\
\text { Beta }\end{array}$} & \multirow[t]{2}{*}{$t$} & \multirow[t]{2}{*}{$p$-Value } \\
\hline & & B & Std. error & & & \\
\hline \multirow[t]{5}{*}{ GAD-7 } & Age & 0.147 & 0.057 & 0.167 & 2.592 & 0.010 \\
\hline & Gender & 2.487 & 0.603 & 0.173 & 4.127 & 0.000 \\
\hline & Level of education & 0.577 & 0.508 & 0.074 & 1.137 & 0.256 \\
\hline & $\begin{array}{l}\text { Tested for } \\
\text { COVID-19 }\end{array}$ & 0.338 & 0.676 & 0.023 & 0.500 & 0.617 \\
\hline & $\begin{array}{l}\text { Reported for } \\
\text { COVID-19 } \\
\text { symptoms }\end{array}$ & 1.754 & 0.750 & 0.108 & 2.338 & 0.020 \\
\hline \multirow[t]{5}{*}{ PHQ-9 } & Age & 0.153 & 0.063 & 0.158 & 2.413 & 0.016 \\
\hline & Gender & 0.985 & 0.639 & 0.065 & 1.541 & 0.124 \\
\hline & Level of education & 1.327 & 0.563 & 0.155 & 2.358 & 0.019 \\
\hline & $\begin{array}{l}\text { Tested for } \\
\text { COVID-19 }\end{array}$ & 0.405 & 0.744 & 0.025 & 0.544 & 0.586 \\
\hline & $\begin{array}{l}\text { Reported for } \\
\text { COVID-19 } \\
\text { symptoms }\end{array}$ & 1.264 & 0.851 & 0.069 & 1.484 & 0.138 \\
\hline
\end{tabular}

Abbreviations: B, the rate of change per unit between dependent and independent variables; Beta, denotes the correlation between variables; COVID19, corona virus disease 2019; GAD, Generalized Anxiety Disorder; PHQ, Patient Heath Questionnaire; SARS-CoV-2, severe acute respiratory syndrome coronavirus 2; Std., standard deviation; $t$, test of the regression coefficients.

Note: $p$-Value, level of significance after comparison with independent variables.

Table 4 Characteristics of PHQ-9 scale $(N=523)$

\begin{tabular}{|l|l|l|l|}
\hline & Patient PHQ-9 score in last 2 wk & Mean & SD \\
\hline PHQ-1 & Little interest or pleasure in doing things & 1.12 & 1.076 \\
\hline PHQ-2 & Feeling down, depressed, or hopeless & 1.05 & 1.042 \\
\hline PHQ-3 & Trouble falling or staying asleep, or sleeping too much & 0.90 & 1.050 \\
\hline PHQ-4 & Feeling tired or having little energy & 1.17 & 1.033 \\
\hline PHQ-5 & Poor appetite or overeating & 0.60 & 0.890 \\
\hline PHQ-6 & Feeling bad about yourself-or that you are a failure or have let yourself or your family down & 0.86 & 1.040 \\
\hline PHQ-7 & Trouble concentrating on things, such as reading the newspaper or watching television & 0.75 & 0.994 \\
\hline PHQ-8 & $\begin{array}{l}\text { Moving or speaking so slowly that other people could have noticed? Or the opposite-being } \\
\text { so fidgety or restless that you have been moving around a lot more than usual }\end{array}$ & 0.31 & 0.698 \\
\hline PHQ-9 & Thoughts that you would be better off dead or of hurting yourself in some way & 0.52 & 0.918 \\
\hline & & $7.30^{\text {a }}$ & 6.166 \\
\hline
\end{tabular}

Abbreviations: PHQ, Patient Heath Questionnaire; SD, standard deviation.

aModerate depression level. 
of health science students in terms of level of depression and anxiety. Overall, $23 \%$ of our sample showed moderate to severe depression. This is consistent with reported literature which mostly shows prevalence of depression to range from 18 to $48 \%$ approximately. ${ }^{20-24}$ About $44 \%$ of our sample showed moderate to severe anxiety. A study done by Özdin and Bayrak Özdin to explore anxiety-related symptoms in Turkey showed a similar prevalence of $45 \%$; however, Spain and China have reported lower levels of anxiety around 21 and $22 \%$, respectively. ${ }^{20,22}$ This variation in prevalence could be because of the use of different scales of scoring or it may represent racial and cultural differences. Moreover, due to difference in stage of pandemic among different countries, the development of symptoms might be varied.

Our study showed a significant association of anxiety ( $p$ $=0.00)$ and depression $(p=0.016)$ with younger age of participants. This is parallel to studies conducted by Qin et al and Wang et al who also reported younger age group to be associated with psychologic symptoms. ${ }^{25,26}$ Observation of more symptoms in age may be due to age-related hormonal disturbances, limitation of outdoor activities, and more access to social media-related disinformation. Regarding association of gender, depression scores did not show significant difference; however, symptoms of anxiety were more commonly observed in females. This may be due to the fact that women, on exposure to different stress situations, have been reported to show differential neurobiological responses. ${ }^{27,28}$ This may also be due to the fact that women have more caregiving household responsibilities which may increase their stress.

We observed a great impact on mental health of undergraduate students, with a rise in depression-related symptoms as years of education increase. This was indicated by a significant difference between education level and PHQ-9 score $(p=0.019)$. A similar observation was made by Cellini et al in their study where university students reported higher level of depression scores as compared with the workers. ${ }^{29}$ The increased depression with higher level of education status may be due to examination-related stress, compromised access and/or comprehension of online classes, and foreseeing delay in examination with eventual outcome of challenges of job opportunities.

About $83 \%$ of our sample population knew a patient who contracted novel COVID-19 infection which seems to impact individuals in terms of increase in anxiety. Watching constant suffering of community members due to COVID-19 probably creates apprehensions. This is especially true for individuals who have comorbidities which were found in $6.1 \%$ of our study population. Studies have shown that people with chronic diseases and associated distressing symptoms are more likely to show local and systematic symptoms of anxiety. ${ }^{30}$ This may not only be related to likelihood of catching the infection but also due to restricted access to consultation and treatment. ${ }^{31}$

Our study included health sciences students from varied nationalities which generalizes the impact of this pandemic. However, the scope of our study was limited as we did not include school going children and adolescents in our sample which would have helped in identification of symptoms at an early and more vulnerable stage of life.

\section{Conclusion}

Quarantine due to COVID-19 pandemic has a definite impact on mental health of students around the globe. Our study adds to the existing body of information regarding possible psychologic illnesses related to this pandemic and highlights the need of timely designing policies and implementing corrective measures at global level. Keeping the possible future responsibilities of health science students, it is imperative that corrective measures are implemented by health and education authorities to ensure their psychologic well-being.

\section{Funding}

None.

\section{Conflict of Interest}

None declared.

\section{Acknowledgment}

The authors thank all participants involved in the study.

\section{References}

1 Wang C, Zhao H. The impact of COVID-19 on anxiety in Chinese university students. Front Psychol 2020;11:1168

2 Huang Y, Zhao N. Chinese mental health burden during the COVID-19 pandemic. Asian J Psychiatr 2020;51:102052

3 Gallè F, Sabella EA, Da Molin G, et al. Understanding knowledge and behaviors related to CoViD-19 epidemic in Italian undergraduate students: the EPICO study. Int J Environ Res Public Health 2020;17(10):3481

4 John Hopkins University. (2020). New Cases of COVID-19 In World Countries. Johns Hopkins Coronavirus Resource Center.https:// coronavirus.jhu.edu/data/new-cases.September 29, 2020

5 Regmi K, Lwin CM. Impact of social distancing measures for preventing coronavirus disease 2019 [COVID-19]: a systematic review and meta-analysis protocol. medRxiv, Available at: https:// www.medrxiv.org/content/10.1101/2020.06.13.2013094v1 doi:10.1101/2020.06.13.20130294 Accessed January 1, 2020

6 Odriozola-González P, Planchuelo-Gómez Á, Irurtia MJ, de Luis-García R. Psychological symptoms of the outbreak of the COVID-19 confinement in Spain [published online ahead of print, 2020 Oct 30]. J Health Psychol 2020;1359105320967086 doi: $10.1177 / 1359105320967086$

7 Marelli S, Castelnuovo A, Somma A, et al. Impact of COVID-19 lockdown on sleep quality in university students and administration staff [published online ahead of print, 2020 Jul 11]. J Neurol 2020;1-8. doi:10.1007/s00415-020-10056-6

8 Basudan S, Binanzan N, Alhassan A. Depression, anxiety and stress in dental students. Int J Med Educ 2017;8:179-186

9 Islam S, Akter R, Sikder T, Griffiths MD. Prevalence and factors associated with depression and anxiety among first-year university students in Bangladesh: a cross-sectional study. Int J Ment Health Addict 2020 doi: 10.1007/s11469-020-00242-y

10 World Health Organization (2018). WHO guidelines: Management of physical health conditions in adults with severe mental disorders. Retrieved from: https://www.who. int/mental_health/evidence/guidelines_severe_mental_disorders_web_note_2018/en/. Accessed February 15, 2020

11 Rotenstein LS, Ramos MA, Torre M, et al. Prevalence of depression, depressive symptoms, and suicidal ideation among 
medical students: a systematic review and meta-analysis. JAMA 2016;316(21):2214-2236

12 Thiemann P, Brimicombe J, Benson J, Quince T. When investigating depression and anxiety in undergraduate medical students timing of assessment is an important factor - a multicentre cross-sectional study. BMC Med Educ 2020;20(1):125

13 Raja HZ, Saleem MN, Saleem T, et al. Perceived stress levels in Pakistani dental students during COVID-19 lockdown. Eur J Den Oral Health 2020;1(4):1-7

14 Ikhlaq A, Bint-E-Riaz H, Bashir I, Ijaz F. Awareness and attitude of undergraduate medical students towards 2019-novel corona virus. Pak J Med Sci 2020;36(COVID19-S4) :S32-S36

15 Kharma MY, Koussa B, Aldwaik A, et al. Assessment of anxiety and stress among dental students to return to training in dental college in COVID-19 era. Eur J Dent 2020;14(suppl S1): S86-S90 doi:10.1055/s-0040-1717052

16 Spitzer RL, Kroenke K, Williams JB, Löwe B. A brief measure for assessing Generalized Anxiety Disorder: the GAD-7. Arch Intern Med 2006;166(10):1092-1097

17 Kroenke K, Spitzer RL, Williams JBW. The PHQ-9: validity of a brief depression severity measure. J Gen Intern Med 2001;16(9):606-613

18 Ahmed MA, Jouhar R, Ahmed N, et al. Fear and practice modifications among dentists to combat novel coronavirus disease (COVID-19) outbreak. Int J Environ Res Public Health 2020;17(8):2821

19 Azad N, Shahid A, Abbas N, Shaheen A, Munir N. Anxiety and depression in medical students of a private medical college. J Ayub Med Coll Abbottabad 2017;29(1):123-127

20 Özdin S, Bayrak Özdin Ş. Levels and predictors of anxiety, depression and health anxiety during COVID-19 pandemic in Turkish society: the importance of gender. Int J Soc Psychiatry 2020;66(5):504-511

21 González-Sanguino C, Ausín B, Castellanos MÁ, et al. Mental health consequences during the initial stage of the 2020 coronavirus pandemic (COVID-19) in Spain. Brain Behav Immun 2020;87:172-176
22 Sønderskov KM, Dinesen PT, Santini ZI, Østergaard SD. The depressive state of Denmark during the COVID-19 pandemic. Acta Neuropsychiatr 2020;32(4):226-228

23 Maqsood A, Sarfraz S, Irfan AB, Faisal A, Fatwani H. Healthcare workers knowledge, practices and stress level amid COVID-19 pandemic. Pak Armed Forces Med J 2020;70(1):S244-S250Q7

24 Gao J, Zheng P, Jia Y, et al. Mental health problems and social media exposure during COVID-19 outbreak. PLoS One 2020;15(4):e0231924 doi:10.1371/journal.pone.0231924

25 Qiu J, Shen B, Zhao M, Wang Z, Xie B, Xu Y. A nationwide survey of psychological distress among Chinese people in the COVID-19 epidemic: implications and policy recommendations. Gen Psychiatr 2020;33(2):e100213 doi:10.1136/ gpsych-2020-100213

26 Wang $\mathrm{H}$, Xia Q, Xiong Z, et al. The psychological distress and coping styles in the early stages of the 2019 coronavirus disease (COVID-19) epidemic in the general mainland Chinese population: a web-based survey. PLoS One 2020;15(5):e0233410

27 Eid RS, Gobinath AR, Galea LAM. Sex differences in depression: insights from clinical and preclinical studies. Prog Neurobiol 2019;176:86-102

28 Gururajan A. Sex differences in susceptibility to depression: a role for LncRNAs. Neuron 2020;106(6):871-872

29 Cellini N, Canale N, Mioni G, Costa S. Changes in sleep pattern, sense of time and digital media use during COVID-19 lockdown in Italy. J Sleep Res 2020;e13074

30 Said OB, Razumova S, Velichko E, Tikhonova S, Barakat H. Evaluation of the changes of salivary $\mathrm{pH}$ among dental students depending on their anxiety level. Eur J Dent 2020;14(4): 605-612

31 Ahmed N, Shakoor M, Vohra F, Abduljabbar T, Mariam Q Rehman MA. Knowledge, awareness and practice of health care professionals amid SARS-CoV-2, corona virus disease outbreak. Pak J Med Sci 2020;36(COVID19-S4):S49-S56 